\title{
PE-HD fatigue damage accumulation under variable loading based on various damage models
}

\author{
M. Bourchak ${ }^{*}$, A. Aid $d^{2,3}$ \\ ${ }^{1}$ Aeronautical Engineering Department, King Abdulaziz University, Jeddah, Saudi Arabia \\ ${ }^{2}$ Laboratoire LPQ3M, Université de Mascara, BP305 Mascara, Algeria \\ ${ }^{3}$ Laboratoire de Mécanique de Lille, Université de Lille 1, UMR CNRS 8107, 59650 Villeneuve d'Ascq, France
}

Received 2 August 2016; accepted in revised form 30 September

\begin{abstract}
Despite numerous studies on fatigue of polymer materials under variable loading, there is little work on highdensity polyethylene (PE-HD). In this context, an experimental analysis for determining the fatigue strength of PE-100, under constant and variable amplitude loading is presented. Further, the cumulative fatigue damage behavior of PE-100 was experimentally investigated. First, the fatigue curve (S-N: stress vs. number of cycles) was obtained in order to establish the fatigue life of PE-100 subjected to constant stress amplitude. Secondly, Miner's fatigue rule as well as stress-based and energy-based fatigue damage models were used to estimate the cumulative variable amplitude fatigue damage. Comparison between predictions and experimental results showed different trends depending on the choice of prediction model used implying careful fatigue damage consideration when designing under variable amplitude loading.
\end{abstract}

Keywords: mechanical properties, polyethylene, cumulative fatigue damage, viscoelastic behavior, block loading

\section{Introduction}

Owing to their advantageous properties and low cost, polymers are used in a wide range and complex structural applications [1]. However, polymers can exhibit a complex nonlinear behavior due to external factors such as strain rate, temperature and hydrostatic pressure (stress triaxiality). This behavior was the subject of various experimental studies [2-4]. High-density polyethylene (PE-HD) is one of the widely utilized polymers in a diversity of industrial applications due to its multiple advantages that it has over more conventional materials. In this regard, some studies on the fatigue characteristics of PE-HD have been published over the years [5-9]. According to those reports, molecular weight and the degree of crystallization or tie molecule concentration have been found to influence the fatigue characteristics of PE-HD. Additionally, the residual stresses iduced by the production process of the polymer pipe was found to have an effect on the service lifetime of PE-HD [10]. Moreover, it has also been reported that external factors such as the mean stress, frequency, shape and loading history can have a significant effect on the fatigue behavior of PE-HD. Zok and Shinozaki studied the effect of dilatational strain on the damage accumulation during fatigue of polypropylene [11]. They found that irreversibility on each cycle results in an accumulation of damage in the studied polymer, which would ultimately result in failure. However, several studies on both, amorphous and semicrystalline polymers indicated that cavities form during cyclic deformation and the volume fraction of these cavities increases with number of cycles [12-15]. Macroscopically, at room temperature, the fracture of semi-crystalline polymers has a form of ductile tearing caused by bridging between cavities

*Corresponding author, e-mail: mbourchak@kau.edu.sa (C) BME-PT 
$[12,13]$. On the other hand, damage characterization in semi-crystalline polymers at submicroscopic scale and its effect on macroscopic properties has been the subject of other investigations $[14,15]$.

PE-HD is extensively used in water and gas distribution systems. This has provided cheaper solutions in the piping industry constituents and networks, from manufacturing to exploitation, through installation and maintenance. However, the tube system used in service is subject to internal pressure or to external forces that vary in magnitude and frequency. The repetition of these fluctuating loads generates responses that differ depending on the type of loading [16]. Such cyclic loads cause cumulative fatigue damage and cracks that can contribute to rupture of the pipe system [17]. Consequently, it is obvious that these polymeric pipes have a problem that needs special consideration. Experience has shown that low applied stress levels may cause rupture of the pipe in a relatively short service time, especially if the loading is cyclic [18].

It is highly probable that the problems of material fatigue under cyclic loading are associated with the presence of intrinsic defects during the manufacturing process. Such defects can lead to pipe rupture, causing human and economic losses. This will have direct consequences on the durability of the whole system [19]. One of the common practices in industrial laboratories is to carry out hydrostatic tests on pipes. Such tests provide information on material resistance to monotonic loads, but give no information on the behavior of the material under cyclic loading given that the applied stresses are lower than those considered at the design stage [20,21].

Fracture mechanics tools have been used by several authors to analyze the resistance to crack initiation and slow crack growth [7-9, 22, 23]. Furthermore, Frank et al. [22] have used a fracture mechanics extrapolation procedure to predict the remaining lifetime of the polyethylene pipes after up to 30 years in use. They concluded that all the investigated pipes were still in a good working condition and were likely to be sufficiently safe to remain in use.

The aim of this paper is to determine the fatigue strength of PE-100 material, and analyze its fatigue behavior by initially characterizing and determining its fatigue life curve. Then, based on the experimental results, some cumulative damage models that are applicable to metallic materials are examined and evaluated in terms of their accuracy in predicting fatigue life under variable amplitude loading. These fatigue life predictions models are the linear Miner's (LM) rule, damage stress (DS) model and damage energy (DE) model.

\section{Material and experimental procedure \\ 2.1. Material}

In this work, PE-HD grade PE-100 pipes having a $200 \mathrm{~mm}$ outside diameter, a nominal wall thickness range from 11.4 to $12.7 \mathrm{~mm}$ and a $12 \mathrm{~m}$ length are used. Pipes were supplied by STPM CHIALI, an A1gerian company who produces PE-100 pipes for natural gas systems according to EN 1555-1 to 7 and ISO 4437. The scope of this study includes tensile tests and axial fatigue tests. Tensile testing is used for determining the monotonic mechanical properties of PE-HD pipes, which are the bases for establishing several stress amplitude levels for fatigue testing. The specimens for both tensile tests and axial fatigue tests were cut directly from an extruded pipe, following the longitudinal direction, as shown in Figure 1a. Cylinder sections were cut using a guillotine cutter axially and transversally. Then, specimens were fabricated in a Mill 55 CNC Mechanized Center with GE Fanuc (EMCO- Concept Mill), using the geometrical specifications shown in Figure 1b [24, 25]. Technical specifications of the studied PE-100 are summarized in Table 1 as given by the supplier.

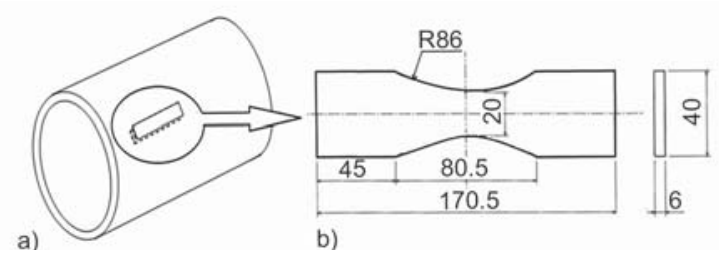

Figure 1. Test specimens: a) test piece cut from the pipe and b) specimen geometry and dimensions in $\mathrm{mm}$ (according to ASTM D-638-Type I)

Table 1. Technical specifications of the studied PE-100

\begin{tabular}{|l|c|c|}
\hline \multicolumn{1}{|c|}{ Characteristic } & Specification & Test method \\
\hline $\begin{array}{l}\text { Hydrostatic pressure } \\
\text { strength }\end{array}$ & $\begin{array}{c}100 \mathrm{~h}: 12.4 \mathrm{MPa}\left(\text { at } 20^{\circ} \mathrm{C}\right) \\
165 \mathrm{~h}: 5.5 \mathrm{MPa}\left(\text { at } 80^{\circ} \mathrm{C}\right)\end{array}$ & ISO 1167 \\
& $1000 \mathrm{~h}: \quad 5.0 \mathrm{MPa}\left(\right.$ at $\left.80^{\circ} \mathrm{C}\right)$ & \\
\hline Elongation at failure & $\geq 350 \%$ & ISO 6259 \\
\hline Density & $\geq 0.930$ & ISO 1183 \\
\hline Fluidity indices & $0.2-1.4 \mathrm{~g} / 10 \mathrm{~min}$ & ISO 1133 \\
\hline Carbon black content & $2-2.5 \%$ & ISO 6964 \\
\hline Oxidation stability & $\geq 20 \mathrm{~min}$ & ISO 10837 \\
\hline
\end{tabular}




\subsection{Static tensile tests}

The static tensile tests were carried out using LLOYD electromechanical testing machine referenced LR150K in the material's laboratory at Higher School of Engineer (HEI, Lille) at room temperature. The tensile machine has a load cell capacity of $5 \mathrm{kN}$ and a crosshead displacement that reaches up to $1150 \mathrm{~mm}$. For the measurement of the local strains in the central zone of the specimen, we used an extensometer (Epsilon Clip-on STAGE) having a base length $L_{0}=$ $50 \mathrm{~mm}$ and allowing displacement measurement between -10 and $100 \%$ of $L_{0}$. The monitoring of the tests and the data acquisition are performed by software of materials analysis named 'NEXYGEN-Plus' developed by LLOYD Instruments [24]. As mentioned in a previous work [24], these static tests were conducted under three crosshead speeds of 5, 10, and $50 \mathrm{~mm} / \mathrm{min}$ corresponding to the strain rates of $10^{-3}$, $2 \cdot 10^{-3}$ and $10^{-2} \mathrm{~s}^{-1}$, respectively. This choice was taken to examine the static tensile response of PE100 and to assess the contribution of viscosity in its mechanical behavior through the influence of the strain rate.

Typical stress-strain curves at different strain rates are given in Figure 2. It is noted that the mechanical behavior of PE-100 is nonlinear and depends on the strain rates. Therefore, it would be of great interest, for a fatigue study, to analyze such an observation. It is noticeable from Figure 2 that the behavior at different strain rates has the same trend. In the domain of small deformations the behavior is elastic and then it is linear viscoelastic. This step is followed by a plastic domain, reached at the maximum point in the stress-strain curve. After that, stress decreases with increasing strain. It is noted that the strain at the threshold of plasticity decreases with increasing strain rate. The elastic modulus $E$ and the yield stress are given in Table 2 whereas Figure 3 shows a number of tested specimens.

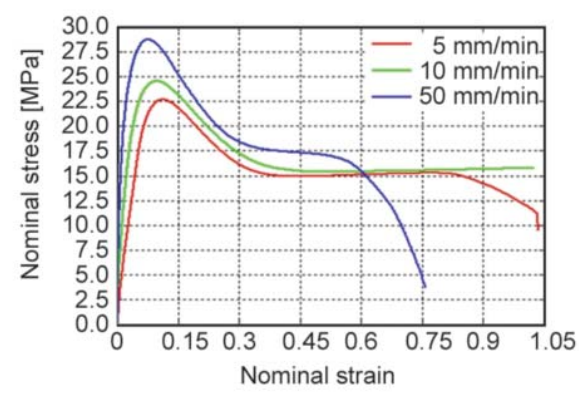

Figure 2. Stress-Strain curves at different strain rates for PE-100

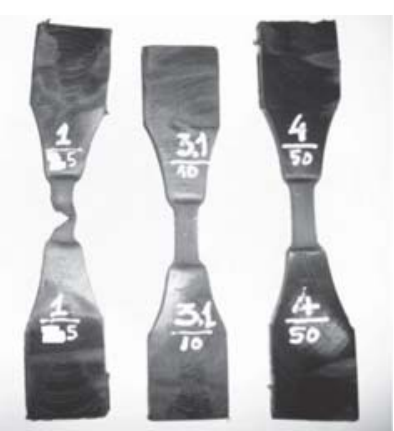

Figure 3. A variety of tensile tested specimensv

Table 2. Quasi static mechanical properties of PE-100

\begin{tabular}{|c|c|c|c|}
\hline $\begin{array}{c}\text { Strain rates } \\
{\left[\mathbf{s}^{-\mathbf{1}}\right]}\end{array}$ & $\begin{array}{c}\text { Yield stress } \\
{[\mathbf{M P a}]}\end{array}$ & $\begin{array}{c}\text { Yield strain } \\
{[\mathbf{\%}]}\end{array}$ & $\begin{array}{c}\text { Young's modulus } \\
{[\mathbf{M P a}]}\end{array}$ \\
\hline $10^{-3}$ & 22.50 & 11.0 & 750 \\
\hline $2 \cdot 10^{-3}$ & 24.50 & 10.0 & 825 \\
\hline $10^{-2}$ & 28.75 & 7.5 & 1400 \\
\hline
\end{tabular}

\subsection{Fatigue tests}

All fatigue tests were carried out at room temperature on the platform of multi-axial test provided in the Mechanics Laboratory of Lille (LML). Initially, the basic fatigue life of the studied PE-100 material was experimentally analyzed. The specimens were fatigue tested under load-control mode, and the stress ratio defined as the ratio of the minimum stress to the maximum stress was set at zero. The shape of the loading waveform is sinusoidal and the employed frequency is $2 \mathrm{~Hz}$ according to ASTM D7791-10 [26]. This low fatigue frequency is chosen so that to avoid specimens heating during cycling because the effect of fatigue tests frequency on polymer is much more pronounced than that of metals $[27,28]$. The main experimental means and information about the test platform and its accessories can be found in [24, 25].

The choice of stress level is dictated by the nature of the fatigue tests on un-notched specimens. For low stress levels, time to failure is excessively long. In addition, we have added in the text, the effect of external loads as the ground movement and the fluctuating weights supported by the soil. These loads generate fluctuating axial stresses. Moreover, the effect of thermal expansions caused by the changes in daily temperatures is also considered. This is the function of the thermal expansion coefficient of the material, the length of the pipeline and the climatic conditions. It can be calculated by Equation (1):

$\Delta L=\alpha \cdot L \cdot \Delta T$

Theoretically, a canalization of $100 \mathrm{~m}$ length will have a thermal expansion of $40 \mathrm{~cm}$ for a temperature 
variation of $20^{\circ} \mathrm{C}$, which is equivalent to a nominal strain of 0.004. In addition, if we consider the nonlinearities and the defects in mechanical joints, the local stresses may reach higher values.

\subsubsection{Cumulative damage tests with two blocks loading}

In the two-block loading fatigue tests, two stress amplitudes were selected as the controlled conditions for each loading block. If the first three cycles of applied stress level are higher than the second stress level, the loading sequence is said to be high-to-low (H-L). While in the reverse case, it is said to be lowto-high (L-H). The residual fatigue life $N_{12}$ is the number of cycles reached until failure of the specimen in the second loading block. $N_{\mathrm{f} 1}$ and $N_{\mathrm{f} 2}$ are lifetimes of the material under $\sigma_{1}$ and $\sigma_{2}$, respectively. Details of these tests are given in Table 3 with the results of the residual life times obtained. Where $\sigma_{1}$ and $\sigma_{2}$ are the applied stresses at the first and the second block, respectively. The prescribed number of cycles at the first bloc is $N_{1}$ and the obtained number of cycles to failure at the second bloc is $N_{2}$.

\subsubsection{Cumulative damage tests with three blocks and random loading}

Blocked program sequences are an approximation of the real loading. However, for studying certain fatigue issues, such as fatigue damage accumulation, blocked spectra can still be used $[29,30]$. In this case, the tests were performed under a program with three blocks loading and random block loading. The $1 / 3$ failure cycle number is applied in the first and the second

Table 3. Sequences of cumulative damage tests and results

\begin{tabular}{|l|l|r|r|r|}
\hline & $\boldsymbol{\sigma}_{\mathbf{1}}$ & $\boldsymbol{\sigma}_{\mathbf{2}}$ & $\boldsymbol{N}_{\mathbf{1}}$ & \multicolumn{1}{|c|}{$\boldsymbol{N}_{\mathbf{2}}$} \\
\hline L-H 1 & 16 & 18 & 2000 & 998 \\
\hline L-H 2 & 18 & 22 & 900 & 182 \\
\hline H-L 1 & 18 & 16 & 900 & 19924 \\
\hline H-L 2 & 22 & 18 & 181 & 851 \\
\hline
\end{tabular}

Table 4. Sequences of cumulative damage tests for 3-block loading

\begin{tabular}{|l|c|c|c|c|c|c|}
\hline & $\begin{array}{c}\boldsymbol{\sigma}_{\mathbf{1}} \\
{[\mathbf{M P a}]}\end{array}$ & $\begin{array}{c}\boldsymbol{\sigma}_{\mathbf{2}} \\
{[\mathbf{M P a}]}\end{array}$ & $\begin{array}{c}\boldsymbol{\sigma}_{\mathbf{3}} \\
{[\mathbf{M P a}]}\end{array}$ & $\begin{array}{c}\boldsymbol{N}_{\mathbf{1}} \\
\text { [Cycle] }\end{array}$ & $\begin{array}{c}\boldsymbol{N}_{\mathbf{2}} \\
{[\text { [Cycle] }}\end{array}$ & $\begin{array}{c}\boldsymbol{N}_{\mathbf{3}}{ }^{*} \\
\text { [Cycle] }\end{array}$ \\
\hline L-H & 16 & 18 & 20 & 1582 & 606 & 301 \\
\hline H-L & 20 & 18 & 16 & 128 & 606 & 3526 \\
\hline Random (1) & 20 & 16 & 18 & 128 & 1582 & 3521 \\
\hline Random (2) & 18 & 16 & 20 & 606 & 1582 & 656 \\
\hline
\end{tabular}

${ }^{*}$ Represent the number of cycles to failure (third block)

block, on the other side, the third block is applied until failure. Experimental results are summarized in Table 4.

Where, $\sigma_{1}, \sigma_{2}$ and $\sigma_{3}$ are the applied stresses at the first, the second and the third block, respectively and $N_{1}, N_{2}$ are the prescribed number of cycles at the first and the second block, respectively, and $N_{3}$ is the obtained number of cycles to failure at the third block.

\subsubsection{Cumulative damage tests with four blocks and random loading}

In this test series, four cyclic stress levels were considered and three different sequences were applied. In the first, second and third block the quarter of failure cycle number is applied, the fourth block is applied until failure. The aim of this set of tests is to determine the influence of increasing and decreasing loading as well as random loading in order to determine the fatigue lifetime under random block loading. The experimental conditions for the blocks loading are given in Table 5. Where, for this case, $\sigma_{4}$ is the applied stress at the fourth block, $N_{3}$ is the prescribed number of cycles at the third block and $N_{4}$ is the obtained number of cycles to failure at the fourth block.

\section{Fatigue damage modelling}

Fatigue lifetimes of the PE-HD material are modeled using three different cumulative damage models which are: linear Miner's (LM) rule, damage stress (DS) model and damage energy (DE) model.

Table 5. Sequences of cumulative damage tests for 4-block loading

\begin{tabular}{|l|c|c|c|c|c|c|c|c|}
\hline & $\begin{array}{c}\boldsymbol{\sigma}_{\mathbf{1}} \\
{[\mathbf{M P a}]}\end{array}$ & $\begin{array}{c}\boldsymbol{\sigma}_{\mathbf{2}} \\
{[\mathbf{M P a}]}\end{array}$ & $\begin{array}{c}\boldsymbol{\sigma}_{\mathbf{3}} \\
{[\mathbf{M P a}]}\end{array}$ & $\begin{array}{c}\boldsymbol{\sigma}_{\mathbf{4}} \\
{[\mathbf{M P a}]}\end{array}$ & $\begin{array}{c}\boldsymbol{N}_{\mathbf{1}} \\
{[\mathbf{C y c l e}]}\end{array}$ & $\begin{array}{c}\boldsymbol{N}_{\mathbf{2}} \\
{[\mathbf{C y c l e}]}\end{array}$ & $\begin{array}{c}\boldsymbol{N}_{\mathbf{3}} \\
{[\mathbf{C y c l e}]}\end{array}$ & $\begin{array}{c}\boldsymbol{N}_{\mathbf{4}}{ }^{*} \\
{[\mathbf{C y c l e}]}\end{array}$ \\
\hline L-H & 16 & 18 & 20 & 22 & 1187 & 454 & 100 & 274 \\
\hline H-L & 22 & 20 & 18 & 16 & 55 & 100 & 454 & 9064 \\
\hline Random (1) & 16 & 20 & 22 & 18 & 1187 & 100 & 55 & 967 \\
\hline Random (2) & 20 & 16 & 18 & 22 & 100 & 1187 & 454 & 201 \\
\hline
\end{tabular}

${ }^{*}$ Represent the number of cycles to failure (fourth block) 


\subsection{Linear Miner's (LM) rule}

For its simplicity and no parameter requirement, we used LM rule to verify how it performs. Miner assumed that the damage represented by the variable $D_{\mathrm{i}}$, and generated by $N_{\mathrm{i}}$ cycles of level $\mathrm{i}$ is, according to Equation (2) [31]:

$D_{\mathrm{i}}=\frac{U_{\mathrm{i}}}{W_{\mathrm{i}}}=\frac{N_{\mathrm{i}}}{N_{\mathrm{f}}}$

By hypothesis, for a sequence loading with $\mathrm{p}$ stress level $(p>0)$, Miner proposed that the rupture occurs when: $\sum_{\mathrm{i}=1}^{\mathrm{i}=\mathrm{p}} D_{\mathrm{i}}=1$.

\subsection{Damage stress (DS) model}

DS model was first proposed by Mesmacque et al. [32], and then further developed by Aid and coworkers [33, 34]. Similar to LM rule, DS model is simple and it only requires the knowledge of the Wöhler curve. An advantage over the LM rule, this nonlinear cumulative model takes into account the load history. Expression of the DS model indicator is given by Equation (3):

$$
D=\frac{\sigma_{\text {edi }}-\sigma_{\mathrm{i}}}{\sigma_{\mathrm{u}}-\sigma_{\mathrm{i}}}
$$

At the first cycle the damage stress is equal to the applied stress, i.e. $D_{\mathrm{i}}=0$ and at the last cycle the damage stress is equal to the ultimate stress and therefore, $D_{\mathrm{i}}=1$. The damage indicator is normalized to 1 at rupture. Damage is then translated to level $i+1$ by the Equation (4):

$D=\frac{\sigma_{\text {edi }}-\sigma_{\mathrm{i}}}{\sigma_{\mathrm{u}}-\sigma_{\mathrm{i}}}=\frac{\sigma_{\text {equiv }}-\sigma_{\mathrm{i}+1}}{\sigma_{\mathrm{u}}-\sigma_{\mathrm{i}+1}}$

where $\sigma_{\text {equiv }}$ and $\sigma_{i+1}$ are damage equivalent stress at level $i+1$ and the applied stress at level $i+1$, respectively. More details can be found in [32-34].

\subsection{Damage energy (DE) model}

DE model is a nonlinear model similar to DS model in the way that it has no parameters to be determined. It only requires Wöhler's curve converted into energy versus number of cycles [35]. Thus, with the assumption that the material behaves elastically during cycling loading, the strain energy density is taken as a variable in the fatigue damage calculation, as shown by Equation (5):

$D=\frac{W_{\text {edi }}-W_{\mathrm{i}}}{W_{\mathrm{u}}-W_{\mathrm{i}}}$ where energy is calculated by the Equation (6):

$W=\frac{1}{2} \sigma \cdot \varepsilon$

The confrontation of the experimental results and prediction results of damage models (LM rule, DS model and DE model) is checked according to the relative error of prediction, denoted as REP. In this investigation, the relative error of prediction represents the relative difference between experimental and calculated lives using the damage models. The REP is defined by Equation (7):

$\operatorname{REP}[\%]=\frac{N_{\text {experimental }}-N_{\text {calculated }}}{N_{\text {experimental }}} \cdot 100$

\section{Results and discussion}

\subsection{Wöhler curve and damage accumulation}

As illustrated by Figure 4, we obtained an almost linear trend between the logarithm of the applied stress versus the logarithm of the number of cycles. Therefore, it is judicious to model the Wöhler curve by Basquin's equation [36]. This latter is commonly used to model the $S-N$ curve of PE-HD material, see [21, 23] and [37]. Thus, parameters of Basquin's equation are given in Equation (8):

$\log \sigma=-0.0728 \log N_{\mathrm{f}}+\log 33.5$

where Basquin [36] proposed a power function between the stress level and the number of cycles as shown by Equation (9):

$\sigma=A \cdot N^{b}$

where $A$ and $b$ are material constants.

Thus, the material constants or Basquin's parameters of the studied PE100 are 33.5 [MPa] and -0.0728 for $A$ and $b$, respectively.

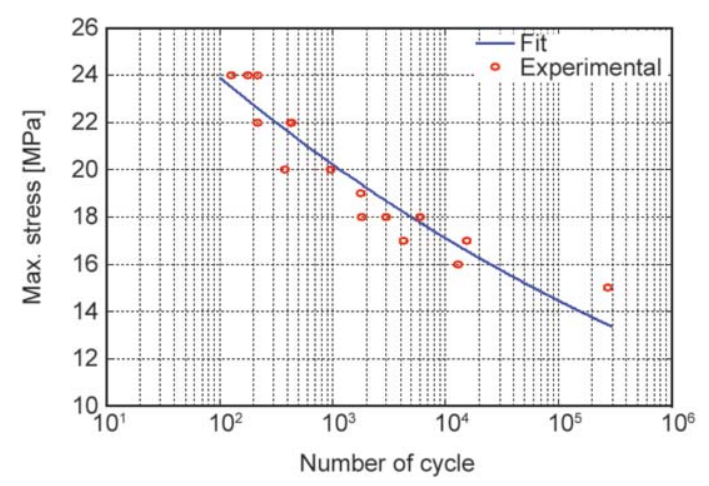

Figure 4. Wöhler's curve for the studied material (PE-100) 
It is noted that, the dispersion results from the same level of loading is already observed. Such a phenomenon is due to several factors, such as manufacturing defects during the process of pipe extrusion and the machining process of specimens.

Examples of fatigue tested specimens under constant loading are shown in Figure 5. The latter clearly shows the dominant process involving the nucleation of damage and its subsequent growth in the form of crazes. As observed, the phenomenon of damage involved is characterized by the necking formation in the middle of the specimen (strain concentration area). Comparably, the fatigued specimens under variables loading exhibits the same damage mode, where one can observe in Figure 6 a local thinning which is produced by a concentration of deformation at the center of the specimen. The last stage of the damage is the appearance of a crack in the middle of the specimen which occurs after an elongation of molecular chains fibrils and the breaking of intermolecular bonds.

It is consequently convenient that the modeling choice made in this study is to use a cumulative damage approach as originally proposed by Miner early in 1945 . This is because it is simple to assess the quality of predictions with such a method that does not require a priori knowledge of damage mechanisms.

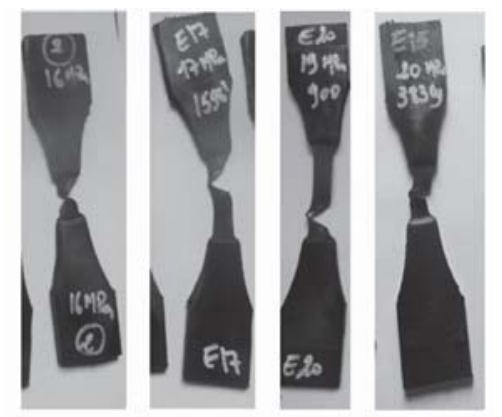

Figure 5. Post fatigue specimens (constant loading)

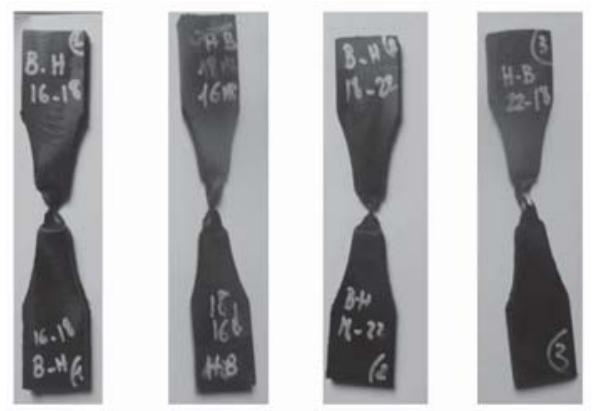

Figure 6. Post fatigued specimens (variable loading)

\subsection{Fatigue life prediction with the nonlinear DE model}

The purpose of this section is to predict fatigue life under constant cyclic loading and to evaluate the fatigue damage after a given number of cycles with a fatigue damage accumulation model which is adopted from literature and adapted to PE-100 material.

DE model is connected to Wöhler's curve (converted to energy curve). Therefore, damage is calculated for each cycle and accumulated until reaching the unit value $(D=1)$. Examples of results obtained from this model are presented in Figure 7, for low-high and high-low sequences and random loading.

Figure 7 shows that the level of loading significantly affects the evolution of the damage. Furthermore, the order of application of stress is considered. Effectively, increasing loading leads to an acceleration of the damage upon the second block. Inversely, when applying a decreasing sequence, the damage diminishes upon the second block loading. This latter observation is interpreted by the slope of the curves, when passing from first to second block.

\subsection{Fatigue life prediction with the DS model}

As the DE model, the DS model is connected to Wöler curve, cycle by cycle. The damage is calculated using a Matlab ${ }^{\circledR}$ program. Using the same calculation principle, except that, the damage parameter is a function of the equivalent stress at a given cycle. Predictions obtained from this model, showed the same trends observed previously when using DE model. Examples of results are given in Figure 8. Where, compared to the DE Model, one can note that the same sequences of loading gave different predictions.

\subsection{Models comparison}

Figure 9 summarizes different residual fatigue lives from the three different models. As is illustrated in Figure 9, Miner's rule gave predictions closer to experimental results.

The results for cumulative damage in the different blocks of loading given in Tables 3, 4 and 5 are summarized in Figure 10. The latter shows that the predictions estimated by the damage models presented in this study are acceptable, since, the most relative errors corresponding to this models are less than $-20 \%$ (more than seven case loading). 

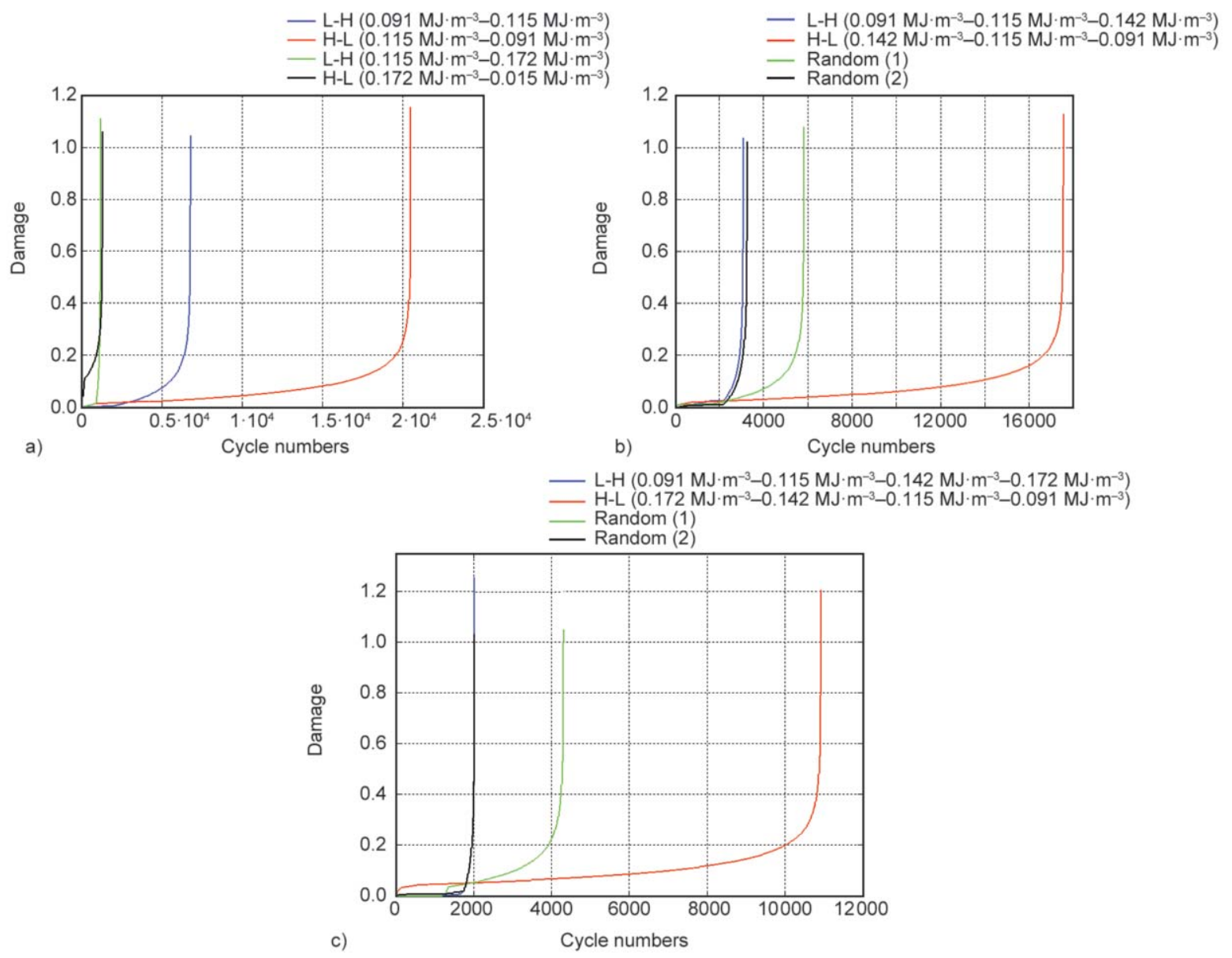

Figure 7. Accumulated damage by the DE model: a) 2-block loading, b) 3-block loading, c) 4-block loading

It is clear from Figure 10 that damage models presented in this study give reasonable results concerning random loading for 3 and 4-block loading where the REP's are less than $20 \%$ except in the case of random (1) relative to the 4-block loading. The results obtained from the models are promising. Indeed, and given the dispersed nature of the fatigue, one can judge the relevance of the predictions obtained from different models.

\section{Conclusions}

In this paper, we have determined the fatigue strength of PE-100 material. Then, we have analyzed its fatigue behavior by characterizing and determining its fatigue life curve. The experimental results served as the basis for modelling accumulation of damage. For this task, we used linear Miner's (LM) rule, damage energy (DE) model and damage stress (DS) model that were originally proposed for metallic materials. Predictions using these different models were investigated and compared to experimental results. In general, the most important findings are as follows:
- The Linear model of Miner by its simplicity proved to be a good predictive tool for Low-High and High-Low sequences.

- The DS model as a nonlinear model gave results closer to that obtained with the LM rule. It seems an adequate model to predict lifetimes of PE-HD. However, results for the two sequences, low to high and high to low, are non-conservative (above experimental results).

- The DE model which is similar to the DS model in concept, overestimates the fatigue lifetimes for both levels of loading, especially, for lowest loading levels. In fact, in this work, we neglected the effect of the viscous dissipated energy, which is added to the elastic energy. This problem will be treated with special attention in future research.

- The loading and the experimental conditions used in the study to validate DE model are lower than the yield stress, so for this reason we neglect the plastic part. For small deformations, the plastic strain energy density is low. In this case, it is assumed that the macroscopic response of the mate- 

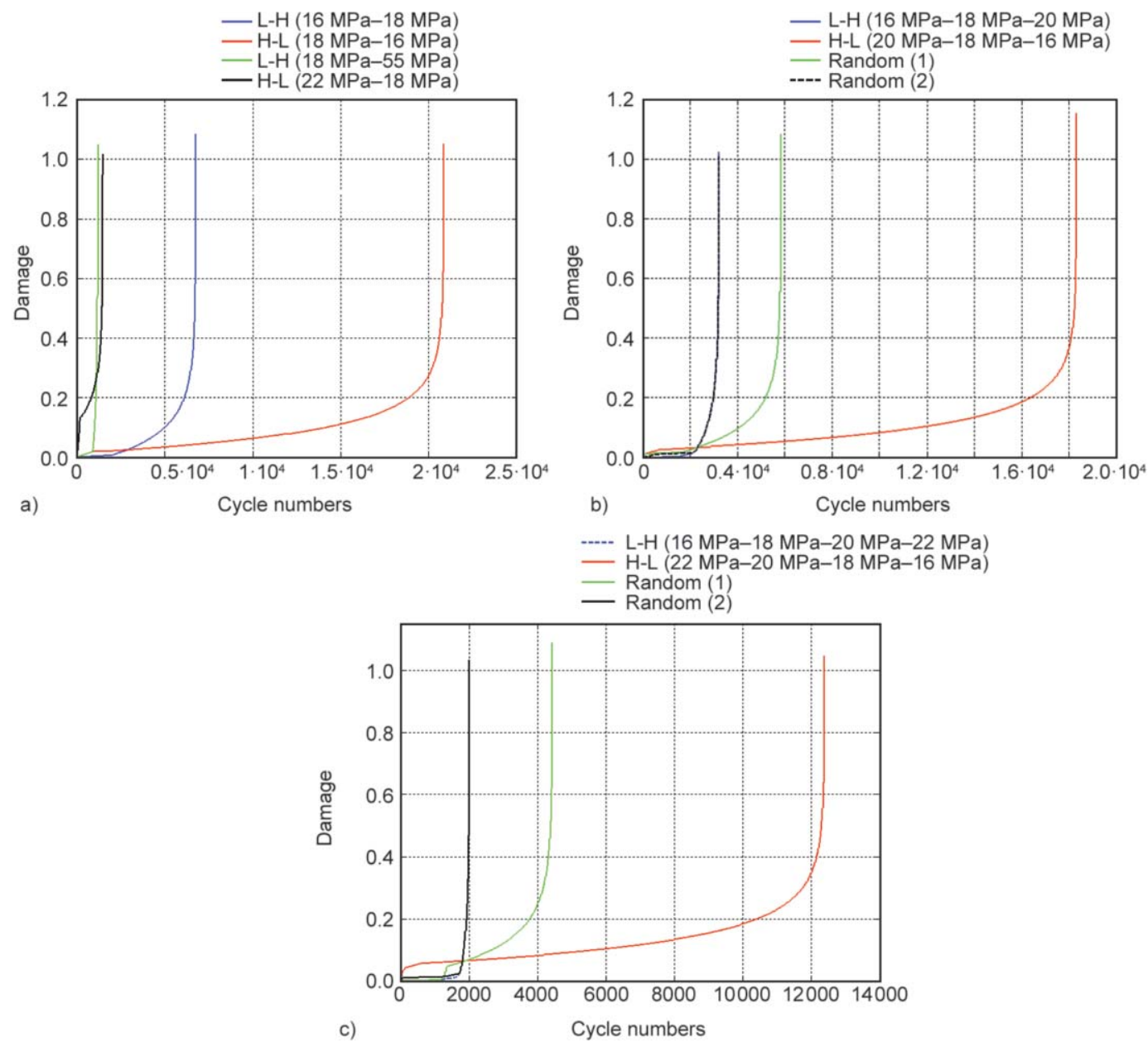

Figure 8. Accumulated damage by the DS model: a) 2-bloc loading, b) 3-block loading, c) 4-block loading

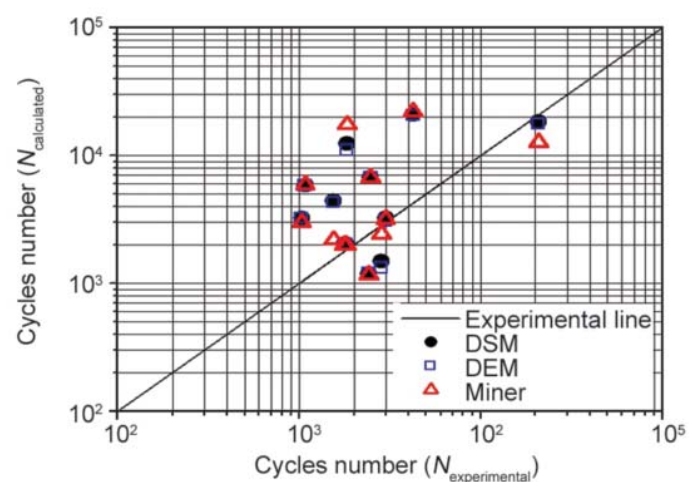

Figure 9. Different model predictions compared to the experimental results

rial is elastic or viscoelastic. Prediction lifetimes obtained by DE model are overestimated and that is probably due to the negligence of viscoelastic strain energy. In all circumstances the current results have led us to revise this model and try to quantify this viscoelastic part by the instantaneous measure of the Stress vs. Strain cycles (area of the hysteresis loop).

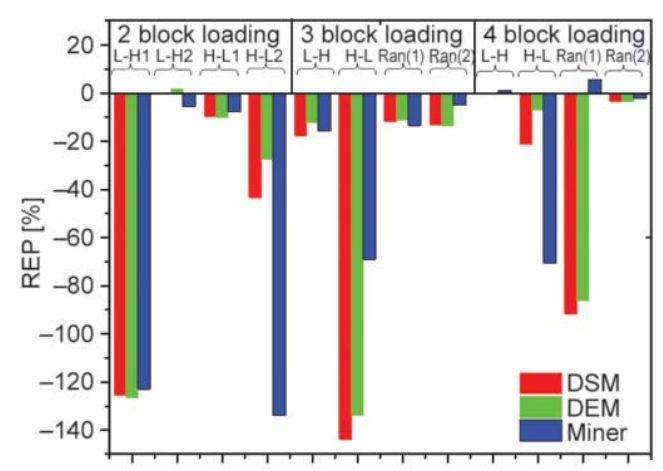

Figure 10. Relative errors of prediction for calculating fatigue lives using the damage models under 2-blocks, 3-blocks and 4-blocks

\section{Acknowledgements}

This work was funded by the Deanship of Scientific Research (DSR), King Abdulaziz University, Jeddah, under grant No. (135-042-D1434). The authors, therefore, acknowledge with thanks DSR technical and financial support. 


\section{Nomenclature}

$\begin{array}{ll}\text { PE-HD } & \text { High-density polyethylene } \\ \text { LM } & \text { Linear Miner's } \\ \text { L-H } & \text { Low-High loading } \\ \text { H-L } & \text { High-Low loading } \\ \text { DE } & \text { Damage energy } \\ \text { DS } & \text { Damage stress } \\ \text { Ran } & \text { Random } \\ \text { REP } & \text { Relative error of prediction } \\ N_{\mathrm{fi}} & \text { Number of cycles to failure for level } i \text { under } \sigma \\ U_{\mathrm{i}} & \text { The work transferred to the specimen for the solicitation } \\ & \text { of amplitude } \sigma \text { applied for } N_{\mathrm{i}} \text { cycles } \\ W_{\mathrm{i}} & \text { Total work transmitted to the specimen at the time of fa- } \\ & \text { tigue failure } \\ W_{\text {edi }} & \text { Energy due to damage stress } \\ W_{\mathrm{i}} & \text { Energy due to the applied stress } \\ W_{\mathrm{u}} & \text { Energy due to the ultimate stress of the material } \\ W & \text { Energy density } \\ \sigma_{\mathrm{edi}} & \text { Damage stress } \\ \sigma_{\mathrm{i}} & \text { Applied stress at i bloc }(i=2,3 \text { or } 4) \\ \sigma_{\mathrm{u}} & \text { Ultimate stress } \\ \sigma & \text { Stress } \\ \varepsilon & \text { Strain }\end{array}$

\section{References}

[1] Brewin J., Chapman P. : Recent developments in the design and manufacture of plastic pipes. Vinidex Tubemakers PTV Limited, Vinidex (2000).

[2] Ognedal A. S., Clausen A. H., Dahlen A., Hopperstad O. S.: Behavior of PVC and HDPE under highly triaxial stress states: An experimental and numerical study. Mechanics of Materials, 72, 94-108 (2014).

https://doi.org/10.1016/j.mechmat.2014.02.002

[3] Ognedal A. S., Clausen A. H., Polanco-Loria M., Benallal A., Raka B., Hopperstad O. S.: Experimental and numerical study on the behaviour of PVC and HDPE in biaxial tension. Mechanics of Materials, 54, 18-31 (2012).

https://doi.org/10.1016/j.mechmat.2012.05.010

[4] Elleuch R., Taktak W.: Viscoelastic behavior of HDPE polymer using tensile and compressive loading. Journal of Materials Engineering and Performance, 15, 111116 (2006).

https://doi.org/10.1361/105994906X83475

[5] Runt J., Jacq M.: Effect of crystalline morphology on fatigue crack propagation in polyethylene. Journal of Materials Science, 24, 1421-1428 (1989).

https://doi.org/10.1007/BF00553177

[6] Nishimura H., Narisawa I.: Fatigue behavior of medium-density polyethylene pipes. Polymer Engineering and Science, 31, 399-403 (1991).

https://doi.org/10.1002/pen.760310603
[7] Strebel J. J., Moet A.: The effects of annealing on fatigue crack propagation in polyethylene. Journal of Polymer Science Part B: Polymer Physics, 33, 1969-1984 (1995). https://doi.org/10.1002/polb.1995.090331312

[8] Lu X., Qian R., Brown N.: The effect of crystallinity on fracture and yielding of polyethylenes. Polymer, 36, 4239-4244 (1995).

https://doi.org/10.1016/0032-3861(95)92219-5

[9] Chen H., Scavuzzo R. J., Srivatsan T. S.: Influence of joining on the fatigue and fracture behavior of high density polyethylene pipe. Journal of Materials Engineering and Performance, 6, 473-480 (1997).

https://doi.org/10.1007/s11665-997-0119-8

[10] Hutař P., Ševčík M., Frank A., Náhlík L., Kučera J., Pinter G.: The effect of residual stress on polymer pipe lifetime. Engineering Fracture Mechanics, 108, 98-108 (2013).

https://doi.org/10.1016/j.engfracmech.2013.04.014

[11] Zok F., Shonozaki D. M.: Dilational damage accumulation during fatigue of polypropylene. Journal of Materials Science, 22, 3995-4001 (1987).

https://doi.org/10.1007/BF01133350

[12] Bhattacharya S. K., Brown N.: Micromechanisms of crack initiation in thin films and thick sections of polyethylene. Journal of Materials Science, 19, 2519-2532 (1984). https://doi.org/10.1007/BF00550806

[13] Bucknall C. B., Dumpleton P.: Fatigue crack growth in polyethylene. Polymer Engineering and Science, 25, 313-317 (1985). https://doi.org/10.1002/pen.760250602

[14] Kuksenko V. S., Ryskin V. S., Betekhtin V. I., Slutsker A. I.: Nucleation of submicroscopic cracks in stressed solids. International Journal of Fracture, 11, 829-840 (1975).

https://doi.org/10.1007/BF00012900

[15] Castagnet S., Girault S., Gacougnolle J. L., Dang P.: Cavitation in strained polyvinylidene fluoride: Mechanical and X-ray experimental studies. Polymer, 41, 7523-7530 (2000). https://doi.org/10.1016/S0032-3861(00)00077-X

[16] Joseph S. H.: Fatigue failure and service lifetimes in PVC pressure pipes. Plastics and Rubber Processing and Applications, 4, 325-330 (1984).

[17] Dowling N. E.: Mechanical behavior of materials : Engineering methods for deformation, fracture, and fatigue. Prentice Hall, New Jersey (1999).

[18] Gardner A. K., King K. B., Cooper J. R.: In-service care considerations for high pressure vessels in a commercial polyethylene process. American Society of Mechanical Engineers, Pressure Vessels and Piping Division, 48, 151-164 (1981). 
[19] Oral E., Malhi A. S., Muratoglu O. K.: Mechanisms of decrease in fatigue crack propagation resistance in irradiated and melted UHMWPE. Biomaterials, 27, $917-$ 925 (2006).

https://doi.org/10.1016/j.biomaterials.2005.06.025

[20] Kannappan S.: Introduction to pipe stress analysis. ABI Enterprises, New York (2008).

[21] Nayyar M. L.: Piping Handbook. 7th Edition, McGrawHill, Singapore (2000).

[22] Frank A., Pinter G., Lang R. W.: Prediction of the remaining lifetime of polyethylene pipes after up to 30 years in use. Polymer Testing, 28, 737-745 (2009). https://doi.org/10.1016/j.polymertesting.2009.06.004

[23] Pinter G., Lang R. W.: Effect of stabilization on creep crack growth in high-density polyethylene. Journal of Applied Polymer Science, 90, 3191-3207 (2003). https://doi.org/10.1002/app.12944

[24] Djebli A., Bendouba M., Aid A., Talha A., Benseddiq N., Benguediab M.: Fatigue life prediction and damage modelling of high-density polyethylene under constant and two-block loading. Procedia Engineering, 101, 2-9 (2015). https://doi.org/10.1016/j.proeng.2015.02.002

[25] Djebli A., Aid A., Bendouba M., Talha A., Benseddiq N., Benguediab M., Zengah S.: Uniaxial fatigue of HDPE100 Pipe. Experimental analysis. Engineering, Technology and Applied Science Research, 4, 600-604 (2014).

[26] ASTM D7791-12: Standard test method for uniaxial fatigue properties of plastics (2014).

[27] Gonzalez M., Machado R., Gonzalez J.: Fatigue analysis of PE-100 pipe under axial loading. in 'Proceeding of the ASME 2011 Pressure Vessels and Piping Conference. Materials and Fabrication, Parts A and B. Baltimore, USA' Vol 6, 905-911 (2011).

[28] Hertzberg R. W., Manson J. A., Skibo M.: Frequency sensitivity of fatigue processes in polymeric solids. Polymer Engineering and Science, 15, 252-260 (1975). https://doi.org/10.1002/pen.760150404

[29] Inoue T., Hoshide T., Yoshikawa T., Kimura Y.: Slipband behavior and crack initiation in polycrystalline copper under multiaxial low-cycle fatigue - A damage mechanics approach. Engineering Fracture Mechanics, 25, 665-675 (1986). https://doi.org/10.1016/0013-7944(86)90031-7
[30] Shamsaei N., Gladskyi M., Panasovskyi K., Shukaev S., Fatemi A.: Multiaxial fatigue of titanium including step loading and load path alteration and sequence effects. International Journal of Fatigue, 32, 1862-1874 (2010). https://doi.org/10.1016/j.ijfatigue.2010.05.006

[31] Miner M. A.: Cumulative damage in fatigue. Journal of Applied Mechanics, 12, A159-A164 (1945).

[32] Mesmcque G., Garcia S., Amrouche A., Rubio Gonzalez C.: Sequential law in multiaxial fatigue, a new damage indicator. International Journal of Fatigue, 27, 461467 (2005).

https://doi.org/10.1016/j.ijfatigue.2004.08.005

[33] Aid A., Bendouba M., Aminallah L., Amrouche A., Benseddiq N., Benguediab M.: An equivalent stress process for fatigue life estimation under multiaxial loadings based on a new non linear damage model. Materials Science and Engineering: A, 538, 20-27 (2012). https://doi.org/10.1016/j.msea.2011.12.105

[34] Aid A., Amrouche A., Bouiadjra B. B., Benguediab M., Mesmacque G.: Fatigue life prediction under variable loading based on a new damage model. Materials and Design, 32, 183-191 (2011). https://doi.org/10.1016/j.matdes.2010.06.010

[35] Djebli A., Aid A., Bendouba M., Amrouche A., Benguediab M., Benseddiq N.: A non-linear energy model of fatigue damage accumulation and its verification for Al2024 aluminum alloy. International Journal of Non-Linear Mechanics, 51, 145-151 (2013). https://doi.org/10.1016/j.ijnonlinmec.2013.01.007

[36] Basquin O. H.: The exponential law of endurance tests. American Society for Testing and Materials Proceedings, 10, 625-630 (1910).

[37] Berrahili A., Castagnet S., Nadot Y.: Multiaxial fatigue criterion for a high-density polyethylene thermoplastic. Fatigue and Fracture of Engineering Materials and Structures, 33, 345-357 (2010). https://doi.org/10.1111/j.1460-2695.2010.01446.x 